Article

\title{
Some Fixed Point Results in $b$-Metric Spaces and $b$-Metric-Like Spaces with New Contractive Mappings
}

\author{
Kapil Jain * and Jatinderdeep Kaur \\ School of Mathematics, Thapar Institute of Engineering and Technology, Patiala 147001, India; jkaur@thapar.edu \\ * Correspondence: kjain_phdp16@thapar.edu
}

check for

updates

Citation: Jain, K.; Kaur, J. Some Fixed Point Results in $b$-Metric Spaces and $b$-Metric-Like Spaces with New Contractive Mappings. Axioms 2021, 10, 55. https://doi.org/10.3390/ axioms10020055

Academic Editor: Wei-Shih Du

Received: 27 February 2021

Accepted: 5 April 2021

Published: 7 April 2021

Publisher's Note: MDPI stays neutral with regard to jurisdictional claims in published maps and institutional affiliations.

Copyright: (c) 2021 by the authors. Licensee MDPI, Basel, Switzerland. This article is an open access article distributed under the terms and conditions of the Creative Commons Attribution (CC BY) license (https:// creativecommons.org/licenses/by/ $4.0 /)$.

\begin{abstract}
The aim of our paper is to present a new class of functions and to define some new contractive mappings in $b$-metric spaces. We establish some fixed point results for these new contractive mappings in $b$-metric spaces. Furthermore, we extend our main result in the framework of $b$-metric-like spaces. Some consequences of main results are also deduced. We present some examples to illustrate and support our results. We provide an application to solve simultaneous linear equations. In addition, we present some open problems.
\end{abstract}

Keywords: $b$-metric space; $b$-metric-like spaces; Cauchy sequence; fixed point

MSC: 47H10; 54H25

\section{Introduction}

The well-known concept of metric space was introduced by M. Frechet [1] as an extension of usual distance. In the theory of metric space, Banach's contraction principle [2] is one of the most important theorems and a powerful tool. A mapping $T: X \rightarrow X$, where $(X, d)$ is a metric space, is called a contraction mapping if there exists $\alpha<1$ such that for all $x, y \in X, d(T x, T y) \leq \alpha d(x, y)$. If the metric space $(X, d)$ is complete, then $T$ has a unique fixed point. Contraction mappings are continuous. In [3], Kannan proved the following result which gives the fixed point for discontinuous mapping: let $T: X \rightarrow X$, be a mapping on a complete metric space $(X, d)$ with

$$
d(T x, T y) \leq \alpha(d(x, T x)+d(y, T y))
$$

where $\alpha \in\left[0, \frac{1}{2}\right)$ and $x, y \in X$. Then, $T$ has a unique fixed point. Contraction mappings have been extended or generalized in several directions by various authors (see, for example, [4-10]). Not only contraction mappings but the concept of metric space is also extended in many ways in the literature (see, for example, [11-19]).

The concept of $b$-metric spaces was initiated by Bakhtin [11] and Czerwik [13,14] as an extension of metric spaces by weakening the triangular inequality.

Definition $1([11,13,14])$. Let $X$ be a non-empty set. Then, a mapping $d: X \times X \rightarrow[0,+\infty)$ is called $a b$-metric if there exists a number $s \geq 1$ such that for all $x, y, z \in X$,

(d1) $d(x, y)=0$ if and only if $x=y$;

(d2) $d(x, y)=d(y, x)$;

(d3) $d(x, z) \leq s(d(x, y)+d(y, z))$.

Then triplet $(X, d, s)$ is called a b-metric space. Clearly, every metric space is a b-metric space with $s=1$, but the converse is not true in general. In fact, the class of b-metric spaces is larger than the class of metric spaces. 
In [14], Banach's contraction principle is proved in the framework of $b$-metric spaces. In 2013, Kir and Kiziltunc established the results in $b$-metric spaces, which generalized the Kannan and Chatterjea type mappings. In [20], the authors introduced the following result that improves Theorem 1 in [21].

Theorem 1 ([20]). Let $(X, d)$ be a complete $b$-metric space with a constant $s \geq 1$. If $T: X \rightarrow X$ satisfies the inequality:

$$
d(T x, T y) \leq \lambda_{1} d(x, y)+\lambda_{2} d(x, T x)+\lambda_{3} d(y, T y)+\lambda_{4}(d(x, T y)+d(T x, y)),
$$

where $\lambda_{i} \geq 0$ for all $i=1,2,3,4$ and $\lambda_{1}+\lambda_{2}+\lambda_{3}+2 \lambda_{4}<1$ for $s \in[1,2]$ and $\frac{2}{s}<\lambda_{1}+\lambda_{2}+$ $\lambda_{3}+2 \lambda_{4}<1$ for $s \in(2,+\infty)$; then, $T$ has a unique fixed point.

In [6], the author introduced quasi-contraction mappings in metric spaces $(X, d)$ : A mapping $T: X \rightarrow X$ is said to be a quasi-contraction if there exists $0 \leq q<1$ such that for any $x, y, \in X$,

$$
d(T x, T y) \leq q \max \{d(x, y), d(x, T x), d(y, T y), d(x, T y), d(T x, y)\} .
$$

Many authors proved fixed point theorems for quasi-contraction mappings in $b$-metric spaces with some more restriction on values of $q$ (see, for example, [20,22-25]). More on $b$-metric spaces can be found in [26-37].

In the present work, we define a new class of functions. After that, we define some new contractive mappings which combine the terms $d(x, y), d(x, T x), d(y, T y), d(x, T y)$ and $d(T x, y)$ by means of the member of a newly defined class. We also prove some fixed point results. To prove our results, we need the following concepts and results from the literature.

Definition 2 ([27]). Let $(X, d, s \geq 1)$ be a b-metric space. Then, a sequence $\left\{x_{n}\right\}$ in $X$ is called:

(i) Cauchy sequence if for each $\epsilon>0$ there exist $n_{0} \in \mathbb{N}$ such that $d\left(x_{n}, x_{m}\right)<\epsilon$ for all $n, m \geq n_{0}$.

(ii) convergent if there exists $l \in X$ such that for each $\epsilon>0$ there exist $n_{0} \in \mathbb{N}$ such that $d\left(x_{n}, l\right)<\epsilon$ for all $n \geq n_{0}$. In this case, the sequence $\left\{x_{n}\right\}$ is said to converge to $l$.

Definition 3 ([27]). A b-metric space $(X, d, s \geq 1)$ is said to be complete if every Cauchy sequence is convergent in it.

Lemma 1 ([29]). Let $(X, d, s \geq 1)$ be a b-metric space and suppose that sequences $\left\{x_{n}\right\}$ and $\left\{y_{n}\right\}$ converge to $x$ and $y \in X$, respectively. Then,

$$
\frac{1}{s^{2}} d(x, y) \leq \liminf _{n \rightarrow+\infty} d\left(x_{n}, y_{n}\right) \leq \limsup _{n \rightarrow+\infty} d\left(x_{n}, y_{n}\right) \leq s^{2} d(x, y) .
$$

In particular, if $x=y$, then $\lim _{n \rightarrow+\infty} d\left(x_{n}, y_{n}\right)=0$.

Moreover, for any $z \in X$, we have

$$
\frac{1}{s} d(x, z) \leq \liminf _{n \rightarrow+\infty} d\left(x_{n}, z\right) \leq \limsup _{n \rightarrow+\infty} d\left(x_{n}, z\right) \leq s d(x, z) .
$$

Lemma 2 ([31]). Every sequence $\left\{x_{n}\right\}$ of elements from a b-metric space $(X, d, s \geq 1)$, having the property that there exists $\lambda \in[0,1)$ such that $d\left(x_{n}, x_{n+1}\right) \leq \lambda d\left(x_{n-1}, x_{n}\right)$ for every $n \in \mathbb{N}$, is Cauchy. 


\section{Fixed Point Results in $b$-Metric Spaces}

In this section, we first define a new class of functions, and then we define a new contractive mapping in $b$-metric spaces as follows.

Definition 4. For any $m \in \mathbb{N}$, we define $\Xi_{m}$ to be the set of all functions $\xi:[0,+\infty)^{m} \rightarrow[0,+\infty)$ such that

( $\left.\xi_{1}\right) \quad \xi\left(t_{1}, t_{2}, \ldots, t_{m}\right)<\max \left\{t_{1}, t_{2}, \ldots, t_{m}\right\}$ if $\left(t_{1}, t_{2}, \ldots, t_{m}\right) \neq(0,0, \ldots, 0)$;

$\left(\xi_{2}\right)$ if $\left\{t_{i}^{(n)}\right\}_{n \in \mathbb{N}}, 1 \leq i \leq m$, are $m$ sequences in $[0,+\infty)$ such that $\limsup _{n \rightarrow+\infty} t_{i}^{(n)}=t_{i}$

$<+\infty$ for all

$i=1$ to $m$, then $\liminf _{n \rightarrow+\infty} \xi\left(t_{1}^{(n)}, t_{2}^{(n)}, \ldots, t_{m}^{(n)}\right) \leq \xi\left(t_{1}, t_{2}, \ldots, t_{m}\right)$.

\subsection{First Main Result}

Definition 5. Let $(X, d, s \geq 1)$ be a b-metric space. The mapping $T: X \rightarrow X$ is said to be an $\xi$-contractive mapping of type-I if there exists $\xi \in \Xi_{4}$ and

$$
d(T x, T y) \leq \frac{1}{s} \xi\left(d(x, y), d(x, T x), d(y, T y), \frac{d(x, T y)+d(T x, y)}{2 s}\right),
$$

for all $x, y \in X$.

Now, the first result of this paper is as follows:

Theorem 2. Let $(X, d, s \geq 1)$ be a complete b-metric space and $T: X \rightarrow X$ be an $\xi$-contractive mapping of type-I. Then, $T$ has a unique fixed point.

Proof. Let $x_{0} \in X$. Define a sequence $\left\{x_{n}\right\}$ in $X$ as $x_{n}=T x_{n-1}$ for all $n \geq 1$. Assume that any two consecutive terms of the sequence $\left\{x_{n}\right\}$ are distinct; otherwise, $T$ has a fixed point. First, we prove that $\left\{x_{n}\right\}$ is a Cauchy sequence. For this, let $n \in \mathbb{N}$.

Consider

$$
\begin{aligned}
d\left(x_{n}, x_{n+1}\right) & \leq \frac{1}{s} \xi\left(d\left(x_{n-1}, x_{n}\right), d\left(x_{n-1}, x_{n}\right), d\left(x_{n}, x_{n+1}\right), \frac{d\left(x_{n-1}, x_{n+1}\right)}{2 s}\right) \\
& <\frac{1}{s} \max \left\{d\left(x_{n-1}, x_{n}\right), d\left(x_{n-1}, x_{n}\right), d\left(x_{n}, x_{n+1}\right), \frac{d\left(x_{n-1}, x_{n+1}\right)}{2 s}\right\} \\
& =\frac{1}{s} \max \left\{d\left(x_{n-1}, x_{n}\right), \frac{d\left(x_{n-1}, x_{n+1}\right)}{2 s}\right\} \\
& \leq \frac{1}{s} \max \left\{d\left(x_{n-1}, x_{n}\right), \frac{d\left(x_{n-1}, x_{n}\right)+d\left(x_{n}, x_{n+1}\right)}{2}\right\},
\end{aligned}
$$

which implies that

$$
d\left(x_{n}, x_{n+1}\right)<\frac{1}{s} d\left(x_{n-1}, x_{n}\right) \quad \text { for all } n \geq 1 .
$$

Case 1: If $s>1$, then by Lemma 2 in view of (3), $\left\{x_{n}\right\}$ is a Cauchy sequence.

Case 2: If $s=1$, then by (3), the sequence $\left\{d\left(x_{n}, x_{n+1}\right)\right\}$ is monotonically decreasing and bounded below. Therefore, $d\left(x_{n}, x_{n+1}\right) \rightarrow k$ for some $k \geq 0$. Suppose that $k>0$; now, taking liminf $n \rightarrow+\infty$ in (2), we have $k \leq \xi\left(k, k, k, k^{\prime}\right)$, where

$$
k^{\prime}=\limsup _{n \rightarrow+\infty} \frac{d\left(x_{n-1}, x_{n+1}\right)}{2} \leq \limsup _{n \rightarrow+\infty} \frac{d\left(x_{n-1}, x_{n}\right)+d\left(x_{n}, x_{n+1}\right)}{2}=k .
$$


Now,

$k \leq \xi\left(k, k, k, k^{\prime}\right)<\max \left\{k, k, k, k^{\prime}\right\}=k$, which is a contradiction; therefore,

$$
\lim _{n \rightarrow+\infty} d\left(x_{n}, x_{n+1}\right)=0 .
$$

Suppose that $\left\{x_{n}\right\}$ is not a Cauchy sequence; then, there exists $\varepsilon>0$ such that for any $r \in \mathbb{N}$, there exists $m_{r}>n_{r} \geq r$ such that

$$
d\left(x_{m_{r}}, x_{n_{r}}\right) \geq \varepsilon
$$

Furthermore, assume that $m_{r}$ is the smallest natural number greater than $n_{r}$ such that (5) holds. Then,

$$
\begin{aligned}
\varepsilon & \leq d\left(x_{m_{r}}, x_{n_{r}}\right) \\
& \leq d\left(x_{m_{r}}, x_{m_{r}-1}\right)+d\left(x_{m_{r}-1}, x_{n_{r}}\right) \\
& <d\left(x_{m_{r}}, x_{m_{r}-1}\right)+\varepsilon \\
& <d\left(x_{r}, x_{r-1}\right)+\varepsilon,
\end{aligned}
$$

thus, using (4) and taking $\lim r \rightarrow+\infty$, we get

$$
\lim _{r \rightarrow+\infty} d\left(x_{m_{r}}, x_{n_{r}}\right)=\varepsilon
$$

Now, consider

$$
d\left(x_{m_{r}+1}, x_{n_{r}+1}\right) \leq \xi\left(d\left(x_{m_{r}}, x_{n_{r}}\right), d\left(x_{m_{r}}, x_{m_{r}+1}\right), d\left(x_{n_{r}}, x_{n_{r}+1}\right), \frac{d\left(x_{m_{r}}, x_{n_{r}+1}\right)+d\left(x_{m_{r}+1}, x_{n_{r}}\right)}{2}\right) .
$$

Therefore, we have

$$
\begin{aligned}
d\left(x_{m_{r}}, x_{n_{r}}\right) \leq & d\left(x_{m_{r}}, x_{m_{r}+1}\right)+d\left(x_{m_{r}+1}, x_{n_{r}+1}\right)+d\left(x_{n_{r}+1}, x_{n_{r}}\right) \\
\leq & d\left(x_{m_{r}}, x_{m_{r}+1}\right)+d\left(x_{n_{r}+1}, x_{n_{r}}\right)+ \\
& \xi\left(d\left(x_{m_{r}}, x_{n_{r}}\right), d\left(x_{m_{r}}, x_{m_{r}+1}\right), d\left(x_{n_{r}}, x_{n_{r}+1}\right), \frac{d\left(x_{m_{r}}, x_{n_{r}+1}\right)+d\left(x_{m_{r}+1}, x_{n_{r}}\right)}{2}\right) .
\end{aligned}
$$

Thus, by taking liminf $r \rightarrow+\infty$ on both sides and also using (4) and (6), we get $\varepsilon \leq 0+0+\xi\left(\varepsilon, 0,0, \varepsilon^{\prime}\right)$, where

$$
\begin{aligned}
\varepsilon^{\prime} & =\limsup _{r \rightarrow+\infty} \frac{d\left(x_{m_{r}}, x_{n_{r}+1}\right)+d\left(x_{m_{r}+1}, x_{n_{r}}\right)}{2} \\
& \leq \limsup _{r \rightarrow+\infty} \frac{d\left(x_{m_{r}}, x_{n_{r}}\right)+d\left(x_{n_{r}}, x_{n_{r}+1}\right)+d\left(x_{m_{r}+1}, x_{m_{r}}\right)+d\left(x_{m_{r}}, x_{n_{r}}\right)}{2} \\
& =\frac{\varepsilon+0+0+\varepsilon}{2}=\varepsilon .
\end{aligned}
$$

Thus, $\varepsilon \leq \xi\left(\varepsilon, 0,0, \varepsilon^{\prime}\right)<\max \left\{\varepsilon, 0,0, \varepsilon^{\prime}\right\}=\varepsilon$, which is a contradiction. Thus, $\left\{x_{n}\right\}$ is a Cauchy sequence in $(X, d, s \geq 1)$.

Now, $(X, d, s \geq 1)$ is a complete $b$-metric space. Therefore, there exists $x \in X$ such that $x_{n} \rightarrow x$.

Now, consider

$$
d\left(T x_{n}, T x\right) \leq \frac{1}{s} \xi\left(d\left(x_{n}, x\right), d\left(x_{n}, T x_{n}\right), d(x, T x), \frac{d\left(x_{n}, T x\right)+d\left(x, T x_{n}\right)}{2 s}\right),
$$


which implies that

$$
d\left(x_{n+1}, T x\right) \leq \frac{1}{s} \xi\left(d\left(x_{n}, x\right), d\left(x_{n}, x_{n+1}\right), d(x, T x), \frac{d\left(x_{n}, T x\right)+d\left(x, x_{n+1}\right)}{2 s}\right) .
$$

Taking $\lim \inf n \rightarrow+\infty$ on both sides and using Lemma 1, we get

$$
\frac{1}{s} d(x, T x) \leq \frac{1}{s} \xi(0,0, d(x, T x), l),
$$

i.e.,

$$
d(x, T x) \leq \xi(0,0, d(x, T x), l)
$$

where

$$
l=\limsup _{n \rightarrow+\infty} \frac{d\left(x_{n}, T x\right)+d\left(x, x_{n+1}\right)}{2 s} \leq \limsup _{n \rightarrow+\infty} \frac{s d(x, T x)+0}{2 s}=\frac{d(x, T x)}{2} .
$$

Thus,

$$
d(x, T x) \leq \xi(0,0, d(x, T x), l)<\max \{0,0, d(x, T x), l\}=d(x, T x),
$$

which is a contradiction. Therefore, $T x=x$.

Let $T y=y$ for some $y \in X$ and suppose that $x \neq y$; then, consider

$$
\begin{aligned}
d(x, y)=d(T x, T y) & \leq \frac{1}{s} \xi\left(d(x, y), d(x, T x), d(y, T y), \frac{d(x, T y)+d(y, T x)}{2 s}\right) \\
& \leq \frac{1}{s} \xi\left(d(x, y), 0,0, \frac{d(x, y)}{s}\right) \\
& <\frac{1}{s} \max \left\{d(x, y), 0,0, \frac{d(x, y)}{s}\right\} \\
& =\frac{d(x, y)}{s},
\end{aligned}
$$

which is a contradiction. Therefore, $x=y$.

Now, the following remark improves our main result for Theorem 2.

Remark 1. Theorem 2 is also valid if the term $\frac{d(x, T y)+d(T x, y)}{2 s}$ in (1) is replaced by $\frac{d(x, T y)+d(T x, y)}{\delta s}$, where $\delta$ is a real number defined by

$$
\delta=\left\{\begin{array}{cc}
2, & \text { if } s=1, \\
\delta^{\prime}, & \text { if } 1<s \leq 2, \\
1, & \text { if } s>2,
\end{array}\right.
$$

where $\delta^{\prime}$ is any number in $\left(\frac{2}{s}, 1+\frac{1}{s}\right)$.

Now, the following result is a consequence of Theorem 2.

Corollary 1. Let $(X, d, s \geq 1)$ be a complete $b$-metric space and $T: X \rightarrow X$ be a mapping such that there exists $q \in\left[0, \frac{1}{s}\right)$ and

$$
d(T x, T y) \leq q \max \left\{d(x, y), d(x, T x), d(y, T y), \frac{d(x, T y)+d(T x, y)}{2 s}\right\},
$$

for all $x, y \in X$. Then $T$ has a unique fixed point.

Proof. Let $\xi \in \Xi_{4}$ be defined by $\xi\left(t_{1}, t_{2}, t_{3}, t_{4}\right)=q s \max \left\{t_{1}, t_{2}, t_{3}, t_{4}\right\}$. Then, following Theorem $2, T$ has a unique fixed point. 
In the following example, we see that conditions of Theorem 2 are satisfied, but Corollary 1 is not applicable.

Example 1. Let $X=\left\{\frac{1}{\sqrt{n}}: n \in \mathbb{N}\right\} \cup\{0\}$. Defined $: X \times X \rightarrow[0,+\infty)$ by $d(x, y)=|x-y|^{2}$ for all $x, y \in X$. Then $d$ is a b-metric on $X$ with $s=2$.

Define $T: X \rightarrow X$ by $T\left(\frac{1}{\sqrt{n}}\right)=\frac{1}{\sqrt{2(n+1)}}$ for all $n \in \mathbb{N}$ and $T(0)=0$. Define

$$
\xi\left(t_{1}, t_{2}, t_{3}, t_{4}\right)=\left\{\begin{array}{cc}
\frac{\max \left\{t_{1}, t_{2}, t_{3}, t_{4}\right\}}{1+t_{1}}, & \text { if } t_{1}>0, \\
\frac{1}{2} \max \left\{t_{2}, t_{3}, t_{4}\right\}, & \text { otherwise. }
\end{array}\right.
$$

Now, for all $x, y \in X,(1)$ is satisfied, and thus the conditions of Theorem 2 are satisfied. However, we see that if (7) is satisfied for all $x, y \in X$, we have

$$
d(T x, T y) \leq q N(x, y),
$$

for all $x, y \in X$, where $N(x, y)=\max \left\{d(x, y), d(x, T x), d(y, T y), \frac{d(x, T y)+d(T x, y)}{2 s}\right\}$. So, in particular, we have

$$
d\left(\frac{1}{\sqrt{2(n+1)}}, \frac{1}{\sqrt{2(m+1)}}\right) \leq q N\left(\frac{1}{\sqrt{n}}, \frac{1}{\sqrt{m}}\right) \text { for all } m, n \in \mathbb{N}, m \neq n .
$$

i.e.,

$$
\frac{\left|\frac{1}{\sqrt{n+1}}-\frac{1}{\sqrt{m+1}}\right|^{2}}{N\left(\frac{1}{\sqrt{n}}, \frac{1}{\sqrt{m}}\right)} \leq 2 q \text { for all } m, n \in \mathbb{N} m \neq n .
$$

Now, taking $\lim n, m \rightarrow+\infty$, we get $2 q \geq 1$, which is a contradiction. Thus, Corollary 1 is not applicable for this example.

Remark 2. In view of Remark 1, Corollary 1 is also valid, if the term $\frac{d(x, T y)+d(T x, y)}{2 s}$ is replaced by $\frac{d(x, T y)+d(T x, y)}{\delta s}$, where $\delta$ is the same as defined in Remark 1.

The following result is another consequence of Theorem 2.

Corollary 2. Let $(X, d, s \geq 1)$ be a complete $b$-metric space and $T: X \rightarrow X$ be a mapping such that

$$
d(T x, T y) \leq \lambda_{1} d(x, y)+\lambda_{2} d(x, T x)+\lambda_{3} d(y, T y)+\lambda_{4}(d(x, T y)+d(T x, y)),
$$

for all $x, y \in X$, where $\lambda_{1}+\lambda_{2}+\lambda_{3}+\delta s \lambda_{4}<\frac{1}{s}$ and $\lambda_{i} \geq 0$ for all $i=1$ to 4 . Then, $T$ has a unique fixed point.

Proof. Let $\xi \in \Xi_{4}$ be defined by $\xi\left(t_{1}, t_{2}, t_{3}, t_{4}\right)=s\left(\lambda_{1} t_{1}+\lambda_{2} t_{2}+\lambda_{3} t_{3}+\delta s \lambda_{4} t_{4}\right)$. Then, by Theorem 2 and Remark $2, T$ has a unique fixed point.

\subsection{Second Main Result}

Now, we define another contractive mapping in $b$-metric space.

Definition 6. Let $(X, d, s \geq 1)$ be a b-metric space. The mapping $T: X \rightarrow X$ is said to be an $\xi$-contractive mapping of type-II if there exists $\xi \in \Xi_{5}$ and

$$
d(T x, T y) \leq \frac{1}{s} \xi\left(d(x, y), d(x, T x), d(y, T y), \frac{d(x, T y)}{2 s}, d(T x, y)\right),
$$


for all $x, y \in X$.

The proof of our next result proceeds in a similar manner as the proof of Theorem 2.

Theorem 3. Let $(X, d, s \geq 1)$ be a complete $b$-metric space and $T: X \rightarrow X$ be an $\xi$-contractive mapping of type-II. Then $\mathrm{T}$ has a unique fixed point.

The following remark improves Theorem 3.

Remark 3. Theorem 3 is also valid, if the term $\frac{d(x, T y)}{2 s}$ in (9) is replaced by $\frac{d(x, T y)}{\delta s}$, where $\delta$ is the same as in Remark 1.

Corollary 3. Let $(X, d, s \geq 1)$ be a complete b-metric space and $T: X \rightarrow X$ be a mapping such that there exists $q \in\left[0, \frac{1}{s}\right)$ and

$$
d(T x, T y) \leq q \max \left\{d(x, y), d(x, T x), d(y, T y), \frac{d(x, T y)}{\delta s}, d(T x, y)\right\},
$$

for all $x, y \in X$. Then, $T$ has a unique fixed point.

Proof. Let $\xi \in \Xi_{5}$ be defined by $\xi\left(t_{1}, t_{2}, t_{3}, t_{4}, t_{5}\right)=q s \max \left\{t_{1}, t_{2}, t_{3}, t_{4}, t_{5}\right\}$. Then, by Theorem $3, T$ has a unique fixed point.

Corollary 4. Let $(X, d, s \geq 1)$ be a complete $b$-metric space and $T: X \rightarrow X$ be a mapping such that

$$
d(T x, T y) \leq \lambda_{1} d(x, y)+\lambda_{2} d(x, T x)+\lambda_{3} d(y, T y)+\lambda_{4} d(x, T y)+\lambda_{5} d(T x, y),
$$

for all $x, y \in X$, where $\lambda_{1}+\lambda_{2}+\lambda_{3}+\delta s \lambda_{4}+\lambda_{5}<\frac{1}{s}$ and $\lambda_{i} \geq 0$ for all $i=1$ to 5 . Then, $T$ has a unique fixed point.

Proof. Let $\xi \in \Xi_{5}$ be defined by $\xi\left(t_{1}, t_{2}, t_{3}, t_{4}, t_{5}\right)=s\left(\lambda_{1} t_{1}+\lambda_{2} t_{2}+\lambda_{3} t_{3}+\delta s \lambda_{4} t_{4}+\lambda_{5} t_{5}\right)$. Then by Theorem 3, $T$ has a unique fixed point.

\section{Fixed Point Results in $b$-Metric-Like Spaces}

Partial metric spaces were introduced by Matthews (1992) as a generalization of metric spaces. The self-distance may be non-zero in partial metric space. In 2012, A. A. Harandi generalized the concept of the partial metric by establishing a new space named the metric-like-space. We notice that in metric-like space, the self-distance of a point may be greater than the distance of that point to any other point (see Example 2.2 in [15]). Later on, S. Shukla (2014) presented the idea of the partial $b$-metric as a generalization of the partial metric and $b$-metric. Meanwhile, in 2013, M.A. Alghamdi et al. introduced the concept of $b$-metric-like spaces that generalized the notions of partial $b$-metric space and metric-like space. Obviously, $b$-metric-like space generalizes all abstract spaces that we have mentioned in our paper. For the sake of clarity, we recall the definitions of these abstract spaces as follows.

Definition 7 ([12]). Let $X$ be a non-empty set. Then, a mapping $d: X \times X \rightarrow[0,+\infty)$ is called a partial metric if for all $x, y, z \in X$,

$$
\begin{aligned}
& (p 1) \quad d(x, y)=0 \Leftrightarrow d(x, x)=d(x, y)=d(y, y) \\
& (p 2) \quad d(x, x) \leq d(x, y) \\
& (p 3) \quad d(x, y)=d(y, x) \\
& (p 4) \quad d(x, z) \leq d(x, y)+d(y, z)-d(y, y)
\end{aligned}
$$


Then, the pair $(X, d)$ is called a partial metric space.

Definition $8([15,38])$. Let $X$ be a non-empty set. Then, a mapping $d: X \times X \rightarrow[0,+\infty)$ is called a metric-like space if for all $x, y, z \in X$,

$$
\begin{aligned}
& (m l 1) \quad d(x, y)=0 \Rightarrow x=y \\
& (m l 2) \quad d(x, y)=d(y, x) \\
& (m l 3) \quad d(x, z) \leq d(x, y)+d(y, z) .
\end{aligned}
$$

Then, the pair $(X, d)$ is called a metric-like space.

Definition 9 ([17]). Let $X$ be a non-empty set. Then, a mapping $d: X \times X \rightarrow[0,+\infty)$ is called a partial $b$-metric if there exists a number $s \geq 1$ such that for all $x, y, z \in X$,

$$
\begin{array}{ll}
(p b 1) & d(x, y)=0 \Leftrightarrow d(x, x)=d(x, y)=d(y, y) ; \\
(p b 2) & d(x, x) \leq d(x, y) ; \\
(p b 3) & d(x, y)=d(y, x) ; \\
(p b 4) & d(x, z) \leq s(d(x, y)+d(y, z))-d(y, y) .
\end{array}
$$

Then, the triplet $(X, d, s)$ is called a partial $b$-metric space.

Definition 10 ([16]). Let $X$ be a non-empty set. Then, a mapping $d: X \times X \rightarrow[0,+\infty)$ is called a $b$-metric-like if there exists a number $s \geq 1$ such that for all $x, y, z \in X$,

$$
\begin{array}{ll}
(b m l 1) & d(x, y)=0 \Rightarrow x=y \\
(b m l 2) & d(x, y)=d(y, x) \\
(b m l 3) & d(x, z) \leq s(d(x, y)+d(y, z)) .
\end{array}
$$

Then, the triplet $(X, d, s)$ is called a b-metric-like space.

The following definitions and results related to $b$-metric-like spaces are required in the main results of this section.

Definition 11 ([16,39]). Let $(X, d, s \geq 1)$ be a b-metric-like space and let $\left\{x_{n}\right\}$ be a sequence of points of $X$. A point $x \in X$ is said to be the limit of sequence $\left\{x_{n}\right\}$ if $\lim _{n \rightarrow+\infty} d\left(x, x_{n}\right)=d(x, x)$, and we say that the sequence $\left\{x_{n}\right\}$ is convergent to $x$ and denote it by $x_{n} \rightarrow x$ as $n \rightarrow+\infty$.

Definition 12 ([16,39]). Let $(X, d, s \geq 1)$ be a b-metric-like space.

(i) A sequence $\left\{x_{n}\right\}$ in $X$ is called Cauchy sequence if $\lim _{n, m \rightarrow+\infty} d\left(x_{n}, x_{m}\right)$ exists and is finite.

(ii) $(X, d, s \geq 1)$ is said to be complete if every Cauchy sequence $\left\{x_{n}\right\}$ in $X$ converges to $x \in X$ so that

$$
\lim _{n, m \rightarrow+\infty} d\left(x_{n}, x_{m}\right)=d(x, x)=\lim _{n \rightarrow+\infty} d\left(x_{n}, x\right) .
$$

Proposition 1 ([16]). Let $(X, d, s \geq 1)$ be a b-metric-like space and $\left\{x_{n}\right\}$ be a sequence in $X$ such that for some $x \in X, \lim _{n \rightarrow+\infty} d\left(x_{n}, x\right)=0$. Then,
(i) $x$ is unique.
(ii) $\frac{1}{s} d(x, y) \leq \lim _{n \rightarrow+\infty} d\left(x_{n}, y\right) \leq s d(x, y)$ for all $y \in X$. 
Lemma 3 ([40]). Let $(X, d, s \geq 1)$ be a b-metric-like space and $\left\{x_{n}\right\}$ be a sequence in $X$ such that

$$
d\left(x_{n}, x_{n+1}\right) \leq \lambda d\left(x_{n-1}, x_{n}\right)
$$

for some $\lambda \in[0,1)$ and for each $n \in \mathbb{N}$. Then, $\left\{x_{n}\right\}$ is a Cauchy sequence with $\lim _{n, m \rightarrow+\infty} d\left(x_{n}, x_{m}\right)=$ 0.

Now, we extend Theorem 2 in the framework of a $b$-metric-like space. At the end of the proof, we provide an example in support.

Theorem 4. Let $(X, d, s \geq 1)$ be a complete b-metric-like space. Let $T: X \rightarrow X$ be a mapping such that there exists $\xi \in \Xi_{4}$ and

$$
d(T x, T y) \leq \frac{1}{s} \xi\left(d(x, y), d(x, T x), d(y, T y), \frac{d(x, T y)+d(T x, y)-d(y, y)}{2 s}\right)
$$

for all $x, y \in X$ with $d(x, T y)+d(T x, y) \geq d(y, y)$. Then, $T$ has a unique fixed point.

Proof. Let $x_{0} \in X$. Define a sequence $\left\{x_{n}\right\}$ in $X$ as $x_{n}=T x_{n-1}$ for all $n \geq 1$. Assume that any two consecutive terms of the sequence $\left\{x_{n}\right\}$ are distinct; otherwise, $T$ has a fixed point. First, we prove that $\left\{x_{n}\right\}$ is a Cauchy sequence. For this, let $n \in \mathbb{N}$.

Now,

$$
d\left(x_{n-1}, T x_{n}\right)+d\left(T x_{n-1}, x_{n}\right)=d\left(x_{n-1}, x_{n+1}\right)+d\left(x_{n}, x_{n}\right) \geq d\left(x_{n}, x_{n}\right) ;
$$

therefore, using (12), we have

$$
\begin{gathered}
d\left(x_{n}, x_{n+1}\right) \leq \frac{1}{s} \xi\left(d\left(x_{n-1}, x_{n}\right), d\left(x_{n-1}, x_{n}\right), d\left(x_{n}, x_{n+1}\right), \frac{d\left(x_{n-1}, x_{n+1}\right)+d\left(x_{n}, x_{n}\right)-d\left(x_{n}, x_{n}\right)}{2 s}\right) \\
<\frac{1}{s} \max \left\{d\left(x_{n-1}, x_{n}\right), d\left(x_{n-1}, x_{n}\right), d\left(x_{n}, x_{n+1}\right), \frac{d\left(x_{n-1}, x_{n+1}\right)}{2 s}\right\} \\
=\frac{1}{s} \max \left\{d\left(x_{n-1}, x_{n}\right), \frac{d\left(x_{n-1}, x_{n+1}\right)}{2 s}\right\} \\
\leq \frac{1}{s} \max \left\{d\left(x_{n-1}, x_{n}\right), \frac{d\left(x_{n-1}, x_{n}\right)+d\left(x_{n}, x_{n+1}\right)}{2}\right\},
\end{gathered}
$$

which implies that

$$
d\left(x_{n}, x_{n+1}\right)<\frac{1}{s} d\left(x_{n-1}, x_{n}\right) \quad \text { for all } n \geq 1 .
$$

Case 1: If $s>1$, then by Lemma 3 and in view of (14), $\left\{x_{n}\right\}$ is a Cauchy sequence in $(X, d, s \geq 1)$ and $\lim _{n, m \rightarrow+\infty} d\left(x_{n}, x_{m}\right)=0$.

Case 2: If $s=1$, then by (14), the sequence $\left\{d\left(x_{n}, x_{n+1}\right)\right\}$ is monotonically decreasing and bounded below. Therefore, $d\left(x_{n}, x_{n+1}\right) \rightarrow k$ for some $k \geq 0$. Suppose that $k>0$; now, taking liminf $n \rightarrow+\infty$ in (13), we have $k \leq \xi\left(k, k, k, k^{\prime}\right)$, where

$$
k^{\prime}=\limsup _{n \rightarrow+\infty} \frac{d\left(x_{n-1}, x_{n+1}\right)}{2} \leq \limsup _{n \rightarrow+\infty} \frac{d\left(x_{n-1}, x_{n}\right)+d\left(x_{n}, x_{n+1}\right)}{2}=k .
$$

Now, $k \leq \xi\left(k, k, k, k^{\prime}\right)<\max \left\{k, k, k, k^{\prime}\right\}=k$, a contradiction; therefore,

$$
\lim _{n \rightarrow+\infty} d\left(x_{n}, x_{n+1}\right)=0 \text {. }
$$




\section{Furthermore,}

$$
d\left(x_{n}, x_{n}\right) \leq d\left(x_{n}, x_{n+1}\right)+d\left(x_{n+1}, x_{n}\right),
$$

taking $\lim \sup n \rightarrow+\infty$, and using (15) we get

$$
\lim _{n \rightarrow+\infty} d\left(x_{n}, x_{n}\right)=0,
$$

Suppose that $\lim _{n, m \rightarrow+\infty} d\left(x_{n}, x_{m}\right) \neq 0$; then, there exists $\varepsilon>0$ such that for any $r \in \mathbb{N}$, there exists $m_{r}>n_{r} \geq r$ such that

$$
d\left(x_{m_{r}}, x_{n_{r}}\right) \geq \varepsilon
$$

Furthermore, assume that $m_{r}$ is the smallest natural number greater than $n_{r}$ such that (17) holds. Then,

$$
\begin{aligned}
\varepsilon & \leq d\left(x_{m_{r}}, x_{n_{r}}\right) \\
& \leq d\left(x_{m_{r}}, x_{m_{r}-1}\right)+d\left(x_{m_{r}-1}, x_{n_{r}}\right) \\
& <d\left(x_{m_{r}}, x_{m_{r}-1}\right)+\varepsilon \\
& <d\left(x_{r}, x_{r-1}\right)+\varepsilon .
\end{aligned}
$$

Thus, using (15) and taking $\lim r \rightarrow+\infty$, we get

$$
\lim _{r \rightarrow+\infty} d\left(x_{m_{r}}, x_{n_{r}}\right)=\varepsilon
$$

Now, suppose that there exist infinitely many $r$ such that

$$
d\left(x_{m_{r}}, T x_{n_{r}}\right)+d\left(T x_{m_{r}}, x_{n_{r}}\right)<d\left(x_{n_{r}}, x_{n_{r}}\right) .
$$

Taking limsup $r \rightarrow+\infty$, and using (16), we get

$$
\lim _{r \rightarrow+\infty}\left(d\left(x_{m_{r}}, T x_{n_{r}}\right)+d\left(T x_{m_{r}}, x_{n_{r}}\right)\right)=0,
$$

which means that

$$
\lim _{r \rightarrow+\infty}\left(d\left(x_{m_{r}}, x_{n_{r}+1}\right)=\lim _{r \rightarrow+\infty} d\left(x_{m_{r}+1}, x_{n_{r}}\right)\right)=0 .
$$

Now,

$$
\varepsilon=\lim _{r \rightarrow+\infty} d\left(x_{m_{r}}, x_{n_{r}}\right) \leq \limsup _{r \rightarrow+\infty}\left(\left(d\left(x_{m_{r}}, x_{n_{r}+1}\right)+d\left(x_{n_{r}+1}, x_{n_{r}}\right)\right)=0,\right.
$$

which is a contradiction. Therefore, there exists $r_{0} \in \mathbb{N}$ such that for all $r \geq r_{0}, d\left(x_{m_{r}}, T x_{n_{r}}\right)+$ $d\left(T x_{m_{r}}, x_{n_{r}}\right) \geq d\left(x_{n_{r}}, x_{n_{r}}\right)$. Thus, for all $r \geq r_{0}$, using (12),

$$
\begin{aligned}
d\left(x_{m_{r}+1}, x_{n_{r}+1}\right) \leq & \xi\left(d\left(x_{m_{r}}, x_{n_{r}}\right), d\left(x_{m_{r}}, x_{m_{r}+1}\right), d\left(x_{n_{r}}, x_{n_{r}+1}\right), \frac{d\left(x_{m_{r}}, x_{n_{r}+1}\right)+d\left(x_{m_{r}+1}, x_{n_{r}}\right)-d\left(x_{n_{r}}, x_{n_{r}}\right)}{2}\right) . \\
\text { Now, } & \begin{aligned}
d\left(x_{m_{r}}, x_{n_{r}}\right) \leq & d\left(x_{m_{r}}, x_{m_{r}+1}\right)+d\left(x_{m_{r}+1}, x_{n_{r}+1}\right)+d\left(x_{n_{r}+1}, x_{n_{r}}\right) \\
\leq & d\left(x_{m_{r}}, x_{m_{r}+1}\right)+d\left(x_{n_{r}+1}, x_{n_{r}}\right)+ \\
& \xi\left(d\left(x_{m_{r}}, x_{n_{r}}\right), d\left(x_{m_{r}}, x_{m_{r}+1}\right), d\left(x_{n_{r}}, x_{n_{r}+1}\right), \frac{d\left(x_{m_{r}}, x_{n_{r}+1}\right)+d\left(x_{m_{r}+1}, x_{n_{r}}\right)-d\left(x_{n_{r}}, x_{n_{r}}\right)}{2}\right) .
\end{aligned}
\end{aligned}
$$


Thus, by taking liminf $r \rightarrow+\infty$ on both sides and also using (15) and (18), we get $\varepsilon \leq 0+0+\xi\left(\varepsilon, 0,0, \varepsilon^{\prime}\right)$, where

$$
\begin{aligned}
\varepsilon^{\prime} & =\limsup _{r \rightarrow+\infty} \frac{d\left(x_{m_{r}}, x_{n_{r}+1}\right)+d\left(x_{m_{r}+1}, x_{n_{r}}\right)-d\left(x_{n_{r}}, x_{n_{r}}\right)}{2} \\
& \leq \limsup _{r \rightarrow+\infty} \frac{d\left(x_{m_{r}}, x_{n_{r}}\right)+d\left(x_{n_{r}}, x_{n_{r}+1}\right)+d\left(x_{m_{r}+1}, x_{m_{r}}\right)+d\left(x_{m_{r}}, x_{n_{r}}\right)-0}{2} \\
& =\frac{\varepsilon+0+0+\varepsilon}{2}=\varepsilon .
\end{aligned}
$$

Thus, $\varepsilon \leq \xi\left(\varepsilon, 0,0, \varepsilon^{\prime}\right)<\max \left\{\varepsilon, 0,0, \varepsilon^{\prime}\right\}=\varepsilon$, which is a contradiction. Thus, $\left\{x_{n}\right\}$ is a Cauchy sequence in $(X, d, s \geq 1)$ with $\lim _{n, m \rightarrow+\infty} d\left(x_{n}, x_{m}\right)=0$.

Now, $(X, d, s \geq 1)$ is a complete $b$-metric-like space; therefore, there exists $x \in X$ such that $x_{n} \rightarrow x$,

$$
d(x, x)=\lim _{n \rightarrow+\infty} d\left(x_{n}, x\right)=\lim _{n, m \rightarrow+\infty} d\left(x_{n}, x_{m}\right)=0 .
$$

Furthermore, according to Proposition 1, $x$ is unique.

Suppose that $T x \neq x$. Now, consider

$$
d\left(T x_{n}, T x\right) \leq \frac{1}{s} \xi\left(d\left(x_{n}, x\right), d\left(x_{n}, T x_{n}\right), d(x, T x), \frac{d\left(x_{n}, T x\right)+d\left(x, T x_{n}\right)-d(x, x)}{2 s}\right),
$$

i.e.,

$$
d\left(x_{n+1}, T x\right) \leq \frac{1}{s} \xi\left(d\left(x_{n}, x\right), d\left(x_{n}, x_{n+1}\right), d(x, T x), \frac{d\left(x_{n}, T x\right)+d\left(x, x_{n+1}\right)}{2 s}\right) .
$$

Taking $\lim \inf n \rightarrow+\infty$ on both sides and using Proposition 1 , we get

$$
\frac{1}{S} d(x, T x) \leq \frac{1}{s} \xi(0,0, d(x, T x), l)
$$

i.e.,

$$
d(x, T x) \leq \xi(0,0, d(x, T x), l)
$$

where

$$
l=\limsup _{n \rightarrow+\infty} \frac{d\left(x_{n}, T x\right)+d\left(x, x_{n+1}\right)}{2 s} \leq \limsup _{n \rightarrow+\infty} \frac{s d(x, T x)+0}{2 s}=\frac{d(x, T x)}{2} .
$$

Thus,

$$
d(x, T x) \leq \xi(0,0, d(x, T x), l)<\max \{0,0, d(x, T x), l\}=d(x, T x),
$$

which is a contradiction. Therefore, $T x=x$.

Let $T y=y$ for some $y \in X$; then, by (12), $d(y, y)=0$. Now, suppose that $x \neq y$, and consider 


$$
\begin{aligned}
d(x, y) & =d(T x, T y) \\
& \leq \frac{1}{s} \xi\left(d(x, y), d(x, T x), d(y, T y), \frac{d(x, T y)+d(y, T x)-d(x, x)}{2 s}\right), \\
& =\frac{1}{s} \xi\left(d(x, y), d(x, T x), d(y, T y), \frac{d(x, T y)+d(y, T x)}{2 s}\right) \\
& \leq \frac{1}{s} \xi\left(d(x, y), 0,0, \frac{d(x, y)}{s}\right) \\
& <\frac{1}{s} \max \left\{d(x, y), 0,0, \frac{d(x, y)}{s}\right\} \\
& =\frac{d(x, y)}{s}
\end{aligned}
$$

which is a contradiction. Therefore, $x=y$.

Example 2. Let $X=[0,+\infty)$. Define $d: X \times X \rightarrow[0,+\infty)$ by $d(x, y)=(x+y)^{2}$ for all $x, y \in X$. Then, $d$ is b-metric-like on $X$ with $s=2$, but $d$ is not $b$-metric on $X$.

Define $T: X \rightarrow X$ by $T(x)=\frac{x}{2}$. In addition, define $\xi\left(t_{1}, t_{2}, t_{3}, t_{4}\right)=\frac{1}{2} \max \left\{t_{1}, t_{2}, t_{3}, t_{4}\right\}$. Now, for all $x, y \in X$, with $d(x, T y)+d(T x, y) \geq d(y, y)$, (12) in Theorem 4 is satisfied and $T$ has a unique fixed point 0.

\section{Application}

In this section, as an application of Theorem 2, we present the following result which provides a unique solution to simultaneous linear equations.

Theorem 5. Consider a system of linear equations

$$
A x=b
$$

where $A=\left[a_{i j}\right]_{n \times n}$ is an $n \times n$ matrix, $b=\left[b_{i}\right]_{1 \times n}$ is a column vector of constants and $x=\left[x_{i}\right]_{1 \times n}$ is a column matrix of $n$ unknowns. If for each $x=\left[x_{i}\right]_{1 \times n}, y=\left[y_{i}\right]_{1 \times n}$ and $i=1$ to $n$,

$$
\left|\left(a_{i i}+1\right)\left(x_{i}-y_{i}\right)+\sum_{j=1, j \neq i}^{n} a_{i j}\left(x_{j}-y_{j}\right)\right|\left(1+\max _{k=1}^{n}\left|x_{k}-y_{k}\right|\right) \leq\left|x_{i}-y_{i}\right| ;
$$

then, the system has a unique solution.

Proof. Let $X=\left\{\left[x_{i}\right]_{1 \times n} \mid x_{i}\right.$ is real for all $i=1$ to $n, n$ being fixed $\}$ and $d: X \times X \rightarrow$ $[0,+\infty)$ be defined as

$$
d(x, y)=\max _{i=1}^{n}\left|x_{i}-y_{i}\right|
$$

for all $x=\left[x_{i}\right]_{1 \times n}, y=\left[y_{i}\right]_{1 \times n} \in X$. Then, clearly $(X, d)$ is a complete $b$-metric space with constant $s=1$ (i.e. $(X, d)$ is a complete metric space).

Now, define a $n \times n$ matrix $C=\left[c_{i j}\right]$ by

$$
c_{i j}=\left\{\begin{array}{cc}
a_{i j}+1, & \text { if } i=j \\
a_{i j}, & \text { if } i \neq j .
\end{array}\right.
$$

Then, the given system (19) reduces to

$$
x=C x-b .
$$

Condition (20) becomes

$$
\left|\sum_{j=1}^{n} c_{i j}\left(x_{j}-y_{j}\right)\right|\left(1+\max _{k=1}^{n}\left|x_{k}-y_{k}\right|\right) \leq\left|x_{i}-y_{i}\right| \quad \text { for all } i=1,2, \ldots, n .
$$


Now, define a mapping $T: X \rightarrow X$ by

$$
T x=C x-b, \quad \text { where } x \in X .
$$

For $x=\left[x_{i}\right]_{1 \times n}$ and $y=\left[y_{i}\right]_{1 \times n}$, suppose that $T x=u=\left[u_{i}\right]_{1 \times n}$ and $T y=v=\left[v_{i}\right]_{1 \times n}$; then,

$$
u_{i}=\sum_{j=1}^{n} c_{i j} x_{j}-b_{i} \quad(i=1,2, \ldots, n)
$$

and

$$
v_{i}=\sum_{j=1}^{n} c_{i j} y_{j}-b_{i} \quad(i=1,2, \ldots, n)
$$

Define

$$
\xi\left(t_{1}, t_{2}, t_{3}, t_{4}\right)=\left\{\begin{array}{cl}
\frac{\max \left\{t_{1}, t_{2}, t_{3}, t_{4}\right\}}{1+t_{1}}, & \text { if } t_{1}>0, \\
\frac{1}{2} \max \left\{t_{2}, t_{3}, t_{4}\right\}, & \text { otherwise. }
\end{array}\right.
$$

Now, using condition (22),

$$
\begin{aligned}
d(T x, T y) & =\max _{i=1}^{n}\left|u_{i}-v_{i}\right| \\
& =\max _{i=1}^{n}\left|\sum_{j=1}^{n} c_{i j}\left(x_{j}-y_{j}\right)\right| \\
& \leq \max _{i=1}^{n}\left(\frac{\left|x_{i}-y_{i}\right|}{1+\max _{k=1}^{n}\left|x_{k}-y_{k}\right|}\right) \\
& \leq \xi\left(d(x, y), d(x, T x), d(y, T y), \frac{d(x, T y)+d(T x, y)}{2 s}\right) .
\end{aligned}
$$

Thus, it is straightforward to see that the hypothesis of Theorem 2 is satisfied. Therefore, T has a unique fixed point and system (19) has a unique solution.

\section{Conclusions}

In this paper, we have defined a new class of functions, and with the help of this class of functions, we defined some new contractive mappings in $b$-metric spaces. Furthermore, we proved some fixed point results for these contractive mappings. One can easily extend these results to common fixed points for weakly compatible mappings (see [22,41,42]). We improve our main results in Theorems 2 and 3 with the help of Remarks 1 and 3, respectively. Can these results be further improved in terms of $s$ ? More precisely, we present here some open questions as follows.

Open Question 1: Does Theorem 2 hold also if the term $\frac{1}{s}$ (before $\xi$ ) in (1) is replaced by $\alpha$, for some $\alpha \in\left[\frac{1}{s}, 1\right]$ ?

Open Question 2: Does Theorem 3 hold also if the term $\frac{1}{s}$ (before $\xi$ ) in (9) is replaced by $\alpha$, for some $\alpha \in\left[\frac{1}{s}, 1\right]$ ?

Author Contributions: Both authors contributed equally in the planning, execution and analysis of the study. Both authors have read and agreed to the published version of the manuscript.

Funding: This research received no external funding.

Institutional Review Board Statement: Not applicable.

Informed Consent Statement: Not applicable.

Data Availability Statement: Not applicable.

Conflicts of Interest: The authors declare no conflict of interest. 


\section{References}

1. Frechet, M. Sur quelques points duo calcul fonctionel. Rendicouti Mahematicodi Palermo 1906, 22, 1-74. [CrossRef]

2. Banach, S. Sur les operations dans les ensembles abstracts ET leur applications aux equations integrals. Fund. Math. 1922, 3, 133-181. [CrossRef]

3. Kannan, R. Some results on fixed points. Bull. Calcutta Math. Soc. 1972, 25, 727-730. [CrossRef]

4. Meir, A.; Keeler, E. A thorem on contractive mappings. J. Math. Anal. Appl. 1969, 28, 326-329. [CrossRef]

5. Nadler, J. Multivalued contraction mappings. Pac. J. Math. 1969, 30, 475-488. [CrossRef]

6. Ciric, L.B. A generalization of Banachs contraction principle. Proceeding Am. Math. Soc. 1974, 45, 267-273. [CrossRef]

7. Rhoades, B.E. A comparison of various definitions of contractive mappings. Trans. Am. Math. Soc. 1977, 226, 257-290. [CrossRef]

8. Rhoades, B.E. Some theorems on weakly contractive maps. Non-Linear Anal. TMA 2001, 47, 2683-2694. [CrossRef]

9. Samet, B.; Vetro, C.; Vetro, P. Fixed point theorems for $\alpha-\psi$-contractive type mappings. Nonlinear Anal. Theory Methods Appl. 2012, 75, 2154-2165. [CrossRef]

10. Wardowski, D. Fixed points of a new type of contractive mappings in complete metric spaces. Fixed Point Theory Appl. 2012, 2012, 94. [CrossRef]

11. Bakhtin, I.A. The contraction mapping principle in almost metric spaces. Funct. Anal. 1989, 30, $26-37$.

12. Matthews, G.S. Partial Metric Topology; Research Report 212; Dept. of Computer Science, University of Warwick: Coventry, UK, 1992.

13. Czerwik, S. Contraction mappings in b-metric spaces. Acta Math. Inform. Univ. Ostrav.1993, 30, 5-11.

14. Czerwik, S. Nonlinear set-valued contraction mapping in b-metric spaces. Atti Semin. Mat. Fis. Dell'Universita Modena Reeggio Emilia 1998, 46, 263-276.

15. Haranadi, A.A. Metric-like spaces, partial metric spaces and fixed points. Fixed Point Theory Appl. 2012, 2012, 204. [CrossRef]

16. Alghamdi, M.A.; Hussain, N.; Salimi, P. Fixed point and coupled fixed point theorems on $b$-metric-like spaces. J. Inequalities Appl. 2013, 402, 1-25. [CrossRef]

17. Shukla, S. Partial $b$-metric spaces and fixed point theorems. Mediter. J. Math. 2014, 11, 703-711. [CrossRef]

18. Jleli, M.; Samet, B. A Generalized Metric Space and Related Fixed Point Theorems. Fixed Point Theory Appl. $2015,2015,61$. [CrossRef]

19. Jleli, M.; Samet, B. On a new generalization of metric spaces. J. Fixed Point Theory Appl. 2018, 20, 128. [CrossRef]

20. Aleksic, S.; Mitrovic, Z.D.; Radenovic, S. On Some Recent Fixed Point Results For Single and Multivalued Mappings in $b$-metric spaces. Fasc. Math. 2018, 61, 5-16. [CrossRef]

21. Dubey, A.K.; Shukla, R.; Dubey, R. Some fixed point results in b-metric spaces. Asian J. Math. Appl. 2014, 2014 , ama0147.

22. Jovanovic, M.; Kadelburg, Z.; Radenovic, S. Common fixed point results in metric type spaces. Fixed Point Theory Appl. 2010, 210, 978121. [CrossRef]

23. Aydi, H.; Bota, M.F.; Karapinar, E.; Mitrovic, S. A fixed point Theorem for set-valued quasi-contractions in $b$-metric spaces. Fixed Point Theory Appl. 2012, 2012, 88. [CrossRef]

24. Pant, R.; Panicker, R. Geraghty and Ciric type fixed point theorems in b-metric spaces. J. Nonlinear Sci. Appl. 2016, 9, 5741-5755. [CrossRef]

25. Mlaiki, N.; Dedovic, N.; Aydi, H.; Filipovic, M.G.; Mohsin, B.B.; Radenovic, S. Some new observations on Geraghty and Ciric type results in $b$-metric spaces. Mathematics 2019, 7, 643. [CrossRef]

26. Khamsi, M.A.; Hussain, N. KKM mapping in metric type space. Nonlinear Anal. 2010, 73, 3123-3129. [CrossRef]

27. Kir, M.; Kiziltunc, H. On some well known fixed point theorems in b-metric spaces. Turk. J. Anal. Number Theory 2013, 1, 13-16. [CrossRef]

28. Sintunavaat, W.; Plubtieng, S.; Katchang, P. Fixed point results and applications on $b$-metric space endowed with an arbitrary binary relation. Fixed Point Theory Appl. 2013, 2013, 296. [CrossRef]

29. Latif, A.; Parvaneh, V.; Salimi, P.; Al-Mazrooei, A.E. Various Suzuki type theorems in $b$-metric spaces. J. Nonlinear Sci. Appl. 2015, 8, 363-377. [CrossRef]

30. Ozturk, V.; Radenovic, S. Some remarks on $b$-(E.A)-property in b-metric spaces. Springer Plus 2016, 5, 544. [CrossRef]

31. Miculescu, R.; Mihail, A. New fixed point theorems for set-valued contractions in $b$-metric spaces. J. Fixed Point Theory Appl. 2017, 19, 2153-2163. [CrossRef]

32. Suzuki, T. Basic inequality on a $b$-metric space and its applications. J. Inequalities Appl. 2017, 2017, 256. [CrossRef]

33. Huang, H.; Deng, G.; Radenovic, S. Fixed point theorems in $b$-metric spaces with applications to differential equation. J. Fixed Point Theory Appl. 2018, 20, 52. [CrossRef]

34. Karapinar, E.; Czerrwik, S.; Aydi, H. $(\alpha, \psi)$-Meir-Keeler Contraction Mappings in Generalized b-metric spaces. J. Funct. Spaces 2018, 2, 1-4. [CrossRef]

35. Qawaqneh, H.; Noorani, M.S.M.; Shatanawi, W.; Aydi, H.; Alsamir, H. Fixed point results for multivalued contractions in $b$-metric spaces and an application. Mathematics 2019, 7, 132. [CrossRef]

36. Karapinar, E.; Mitrovic, Z.; Ozturk, A.; Radenovic, S.N. On a theorem of Ciric in b-metric spaces. Rendiconti Circolo Matematico Palermo Aeries 2 2021, 70, 217-225. [CrossRef]

37. Mitrovic, Z.; Parvaneh, V.; Mlaiki, N.; Hussain, N.; Radenovic, S.N. On some new generalizations of Nadler contraction in b-metric spaces. Cogent Math. Stat. 2020, 7, 1760189. 
38. Vujakovic, J.; Mitrovic, S.; Mitrovic, Z.D.; Radenovic, S. On F-Contractions for Weak $\alpha$-Admissible Mappings in Metric-Like Spaces. Mathematics 2020, 8, 1629. [CrossRef]

39. Chen, C.; Dong, J.; Zhu, C. Some fixed point theorems in b-metric-like spaces. Fixed Point Theory Appl. 2015, 2015, 122. [CrossRef]

40. Sen, M.D.; Nicolic, N.; Dosenovic, T.; Pavlovic, M.; Radenovic, S. Some Results on (s-q)-Graphic Contraction Mapping in b-Metric-like Spaces. Mathematics 2019, 7, 1190. [CrossRef]

41. Abbas, M.; Jungck, G. Common fixed point results for noncommuting mappings without continiuty in cone metric spaces. J. Math. Anal. Appl. 2008, 341, 416-420. [CrossRef]

42. Jungck, G.; Radenovic, S.; Radojovic, S.; Rakocevic, V. Common fixed point theorems for weakly compatible pairs on cone metric spaces. Fixed Point Theory Appl. 2009, 2009, 643840. [CrossRef] 